\title{
Extent of bullying among school students
}

\author{
Sonia George \\ Assistant Professor and Head, Department of Psychology, Government College for Women, \\ Thiruvananthapuram, Kerala
}

Corresponding author: Sonia George

Email-sonia@mindcarter.com

\begin{abstract}
Background: Bullying is a repeated pattern of harmful verbal, physical or social behavior which involves the misuse of power. Bullying of any form or for any reason can have long -term effects on those involved, including bystanders. The main objective of the study is to find out the extent to which bullying behavior prevails among the school students.

Methods: The sample for the present study was selected from different schools which consist of 300 boys \& 300 girls with a total sample of 600 school students. The main research tool used for the study was the Bullying Questionnaire constructed for the present study, which was given along with the personal data sheet. Data was collected from the students in their respective classrooms, which were then scored, coded, and then analyzed. The statistical techniques used are descriptive statistics namely frequency and percentage.

Results: 10 percent of the students reported that they not safe in their school. It was found that $53.5 \%$ of the students in the study have experienced bullying during the past four weeks.

Conclusion: There is prevalence of bullying behavior among school students in Kerala. There are also differences in the place and time of bullying.
\end{abstract}

Keywords: Extent, Type, Bullying, School students.

(Paper received $-16^{\text {th }}$ April 2018, Peer review completed $-20^{\text {th }}$ May 2018)

(Accepted $-24^{\text {th }}$ May 2018)

\section{INTRODUCTION}

Bullying in schools has become a widespread problem that can have lifelong negative consequences for both the bully and victim. Bullying can be defined as unwanted negative behaviour, verbal, psychological or physical, conducted by an individual or group against another person or persons and which is repeated over time. Bullying is a repeated pattern of harmful verbal, physical or social behaviour which involves the misuse of power. Bullying of any form or for any reason can have long -term effects on those involved, including bystanders [1].

Tattum and Tattum [2] proposed that "Bullying is the wilful conscious desire to hurt another and put him/her under stress". Dan Olweus defined Bullying as "negative behaviour" by which he meant behaviour intended to inflict" injury or discomfort" [3]. According to Ken Rigby "bullying involves an initial desire to hurt, this desire is expressed in action, someone is hurt, the action is directed by a more powerful person or group, it is without justification, it is typically repeated, and it is done so with evident enjoyment" [4].

Bullying has two key components: repeated harmful acts and an imbalance of power. It involves repeated physical, verbal or psychological attacks or intimidation directed against a victim who cannot properly define him or herself because of size or strength, or because the victim is out-numbered or less psychologically resilient. Bullying includes assault, tripping, intimidation, rumour spreading and isolation, 
demands for money, destruction of property, theft of valued possession of another's work, and name calling. Bullying can be done in individual or in group and it can be physical or emotional. There can also be different target groups based on disability, religion, race etc.

The psychology behind the school bullying is a simple construct that those who indulge in bullying desire to dominate and gain power over fellow students. People who bully others are often motivated by the status and social power they can achieve through bullying. Students are victims of a spectrum of problem behaviours at school, ranging from minor disciplinary problems to criminal victimization [3]. Bullying is one form of these problem behaviours that concerns students, educators and parents because of its potential detriment to the student's well - being [5-6].

In an Indian study by Kshirsagar, Agarwal and Bavdekar [7], involving interviews of 500 students aged 8 to 12 at rural schools in Maharashtra, bullying was reported by 31.4 percent of the children surveyed. Teasing and calling names where the commonest forms. Seen, according to the study published in a 2007 issue of Indian paediatrics other forms of bullying - in descending order of incidence -include the use of bad words, spreading rumours, threatening, and causing isolation. Causing physical hurt was reported by 16 percent of the students who were bullied. In another study of 500 children from five randomly selected schools, as many as 60.4 percent of the students experienced similar forms of bullying, but only 39 percent of the victim's parents were aware of it. According to the national centre for educational statistics, nearly a third of all students aged 12-18 reported having been bullied at school in 2007, some almost daily [8].

Bullying in schools is an issue that continues to receive attention from researchers, educators, parents and students. Despite the common assumption that bullying is a normal part of childhood and encompasses minor teasing and harassment [9], some may bully others to compensate for what is happening to them and their own feelings of powerlessness. Bullying in school involve psychological, emotional, cyber, social or physical harassment of one student by another at school or within the school community. It can involve actual or threatened physical violence, verbal abuse or intimidation, written abuse or threats, including graffiti, name calling and teasing, sometimes of a racist, sexist or sexual nature, black mail or other forms of extortion, including theft of students work, exclusion for no good reason.

Bullying affects everyone involved, even people who witness it. It can have serious and long term emotional or psychological consequences in addition to the immediate harmful effects. Communities that condone or ignore bullying may create an environment where more serious anti-social behaviour is condoned. Bullying undermines key values that schools aim to promote in students -respect, trust and honesty. Thus, it is a psychological, social, educational, moral, developmental and cultural problem which demands early identification. This interdisciplinary relevance adds to the importance of the study.

As established by studies in Scandinavian countries, a strong correlation appears to exist between bullying other students during the school years and experiencing legal or criminal troubles. Students who were engaged in bullying in grades 6-9 had at least one criminal conviction by age 24. Chronic bullies seem to maintain positive relationships with antisocial behaviours in the future [10].

Victims often fear school and consider school to be an unhappy place. Almost 7\% of Americans experience low self-esteem which is said to be mainly due to bullying [10]. Many eighth-graders stay home at least once a month because of bullies. The act of being bullied tends to increase some students' isolation because their peers do not want to increase the risks of being bullied themselves. Being bullied can lead to depression and low self-esteem and such problems can also carry themselves in to adulthood [10].

Considering the paucity of data from India and taking in to account the potential of this phenomenon to cause damage to the well-being of young children, a study to determine the prevalence and type of bullying amongst school children is to be undertaken. It has to be noted that no study has been done in Kerala regarding this issue. Every child has the right to a safe, protected school environment. The agony that so many children endure as a result of bullying cannot be ignored. With the ultimate aim of preventing bullying, the following objectives have been set for the conduct of the present study. The main objective of the study is to find out the extent to which bullying behaviour prevails among the school students and to find out when and where bullying mostly happens.

Based on these objectives, the following hypotheses were formulated.

- There will be prevalence of bullying behaviour among school students.

- There will be differences in the place and time of bullying. 


\section{METHODOLOGY}

\section{Sample}

The sample for the present study included school students. The sample was selected from schools in Trivandrum district. The sample consists of 300 boys and 300 girls with a total of 600 school students studying in fifth standard to plus two. Certain socio - demographic factors like age, religion, place of residence, occupation of both father and mother were also considered while collecting the data.

\section{Tools}

The present study was mainly intended to find out the extent to which bullying behaviour prevails among the school students. Therefore, the study required tools to measure the extent of bullying and the personal details of the sample.

The following are the tools used for the study.

- Personal data sheet

- Bullying questionnaire

Personal data sheet: The personal data sheet was prepared to be used in the present study and it consists of 14 items. These 14 items include personal details and family details. The 6 items deal with personal information of the subject. The family details consist of 8 items.

Bullying Questionnaire: The bullying questionnaire was constructed by Sonia George and Reshma S (2016) in connection with the present study to assess the prevalence of bullying among school students. It consists of 44 items measuring 15 different aspects of bullying. Most of the items ask the students about their experiences of bullying at school in the past four weeks. The variables measured include:

- the extent to which students feel safe at school(safety)

- the extent to which students have become victims of bullying (extent of victim)

- the type of bullying experienced as a victim (victim type)

- extent to which bullying has led to the absence of students in school (absence)

- the extent to which bullying in schools bothers them (bothering)

- the type of bullying they have engaged in (bullying type self)

- the type of bullying they have seen or heard being given to others (bullying type others)

- the extent to which they have helped the bullying victims (victim help)

- the extent to which they have been left out or treated badly (bad treatment)

- the place in which bullying happens in school (place of bullying)

- time in school when bullying happens (the bullying time)

- the extent to which they have given help to the bullying victims (bullying help)

- the reason for not providing help to the victims (non- help reason)

- what was their reaction to bullying (bullying reaction)

- the reason for not reacting to bullying (non-reacting reason)

- attitude towards bullying.

The items for the questionnaire were written after consultation with psychologists and school teachers. For this, two focus group discussions were done, one which included psychologists and other which included teachers from different schools. The groups comprised of ten participants.

After item writing, the draft scale was administered to 100 school students. The items were scored and were subjected to item analysis. Items with good discriminatory index and moderate difficulty were included in the final questionnaire.

\section{Administration}

The questionnaire thus constructed was administered to a total of 600 students to get the data for the study. Before distributing the questionnaire, the students need to be given an idea or awareness regarding what bullying is. This required an average of 10 minutes. Then the questionnaire is distributed among the students and instructed as following. "This questionnaire consists of several items related to bullying in schools. Read each item carefully and mark your responses in the space given against each item. You need to think about 
your experiences and answer to the items accordingly". The purpose and confidentiality of the study is also explained. They are requested to mark the preferences honestly. Cooperative participants take 30 minutes for the completion of the questionnaire.

\section{Scoring}

The bullying questionnaire consists of 44 items which measure 15 different variables of bullying. The items from 1 to 6 consist of personal information about the participant. The items $7-9$ correspond to the extent to which students feel safe at school (safety). The scoring system for the items will remain the same throughout the test, namely, $0,1,2,3,4$ as given in the response pattern. The summated score of the items provide the total score for that particular variable.

Before moving on to the next items, descriptions of the types of bullying are given in detail. The items 10-15 correspond to the extent to which students have become victims of bullying (extent of victim). The scoring system for the items is the same $0,1,2,3,4$. The summated score of the items provide a total score of the extent of victim. The items till 15 have a scoring pattern of $0,1,2,3$, and 4 which stands for NO, no, some, yes, YES respectively.

In the item 16 the type of bullying experienced as a victim (victim type) is dealt with. It includes 4 sub items each on are scored in 0, 1, 2, 3, 4. Each type of bullying is scored separately. For the items 16, 17, 19, 20, 21 , and 22, a scoring pattern of Never in 4 weeks, Once or twice every week, many times a week, and Don't know is given which stands for $0,1,2,3$ respectively.

The item number 17 deals with the extent to which bullying have led to the absence of students in school (absence). Item number 18 refers to the extent to the extent to which bullying in schools bothers the student (bothering). Four options are given, from which the student has to select the appropriate one. Next item, which is 19 , asks the subject for the type of bullying they have been engaged in (bullying type self). There also 4 options are given which deals with the type of bullying. The item number 20 asks the students for the type of bullying they have seen or heard as being given to others (bullying type others). Her also the type of bullying is taken into account in the responses.

The next item deals with the extent to which they have helped the bullying victims (victim help). Item number 22 measures the extent to which the students have been left out or treated badly (bad treatment). This item has 14 sub items dealing with the reasons for the bad treatment, if any. The place in which bullying happens in school (place of bullying) is the theme of the next item (23). It gives 14 options for the respondent from which they have to choose the place where bulling mostly happens.

The item 24 asks the respondents about the time in school when bullying happens (the bullying time). It gives 6 options for the students to respond. The next item, i. e., 25 asks for the extent to which they have given help to the bullying victims (bullying help). It gives 13 options to the respondent which deals with the ways they have helped the victims. The reason for not providing help to the victims (non- help reason) was asked in the $26^{\text {th }}$ item. Seven options were given to the students to choose the reason for not helping. The 27 th item asked the students what was their reaction to bullying when they were bullied (bullying reaction). It gave 12 options for response. The next item deals with the reason felt by the students for not reacting to bullying (non-reacting reason). Here the number of options given is 5 .

The final section in the questionnaire deals with the attitude of the students towards bullying. The items from 29 to 44 are included in this section. The response options are like NO, no, some, yes, YES which are given a score of $0,1,2,3$, and 4 respectively. Here, a low score indicates a negative attitude towards bullying, where the students do not support any form of bullying in schools. A high score, on the other hand indicates a positive attitude towards bullying, where the students support bullying in schools.

\section{Data collection procedure}

The data for the present study was collected from schools in Trivandrum District. The first step in collection of data was to identify and select educational institutions. Then the permission of the principal of the schools was sought. Data collection was fixed on a particular day in accordance with the permission of the principal. The schools which gave permissions were again visited on the day of appointment and data collection was done. The researcher met the students in their respective classes. 
The researcher introduced the topic 'bullying' to the students of the class. Then the questionnaires were distributed to students and they were told to read the instructions and fill the questionnaires. Even though a specific time limit was not given, the students were asked to fill in the questionnaires as fast as they can. After completion, the questionnaires were collected back.

\section{STATISTICAL ANALYSIS}

The collected data were scored, coded and analysed. The analysis was done using the statistical package for social sciences (SPSS). Descriptive statistics were used for the analysis of the data. In this study, descriptive statistics, namely, frequency and percentage were used to explore the extent and type of bullying prevailing among the selected sample. Each item of the Bullying Questionnaire was analysed according to the number and percentage of students who have responded to each option. This would give a clear idea about the prevalence of bullying in this particular group.

Frequency: In statistics the frequency (or absolute frequency) of an event is the number of times the event occurred in an experiment or study.

Percentage: A percentage is a number of ratio expressed as a function of 100. It is often denoted using the percent sign, "\%", or the abbreviations- "pct.", "pct"; sometimes the abbreviation "pc" is also used. A percent is a dimension less number (pure number)

\section{RESULTS \& DISCUSSION}

The first objective of the study is to find out the extent to which bullying behaviour prevails among the school students. Many sets of questions were asked to get an idea about the prevalence of bullying among schools. The first set of questions deal with safety of the student. Table no. 1 gives the number and percentage of students with regard to how safe they feel at school.

The questionnaire had three items asking about the extent to which students feel safe at school. From the table, it may be noted that 90 percent of the children reported that they are safe in the school. But, at the same time 10 percent of the children reported that they not safe. It indicates that this 10 percent of the children i.e., 60 out of the total 600 students are experiencing bullying at their school. It means that even though the number and percentage of students may be small, there is a small group of children who are not feeling comfortable at their school and are always worried about something bad that could happen to them. School has to be a home away from home and students should feel the same level of safety and security they feel when they are at home. When that is not the case, it points out to some negative things happening in the school, something that should have to be taken seriously. Here, bullying might play a role and this doubt is explored in the coming sections.

Further items in the bullying questionnaire explore the extent and type of bullying experienced by the students. Items from 10 to 15 ask whether bullying is happening in the school during the past four weeks. A score more than six indicates that bullying has happened during the past four weeks.

It was noted that 321 students scored above 6 compared to the 279 students who scored below 6 . This comes to a percentage of 53.5 who have experienced bullying during the past four weeks. The rest $46.5 \%$ of students report not to have had any experiences with regard to bullying. The main objective of the study is to find out the extent of bullying. The result in the table indicates that among the total sample, more than half report to have been experiencing bullying in their school. This is something to be taken very seriously as this might affect the overall happiness and the productivity of the students. Earlier studies have also been in this line.

Bullying occurs in schools more frequently than one might expect, Paruult, and Pellegrini [11] found that bullying occurred every seven minutes within the school setting. Smokowaski and Kopaz [12] stated that bullying affects approximately one in three children. Bullying seemed to impact every type of students there was no bias as to whom it affects. Bullying occurred equally to boys and girls who had reported being victims. The institute of education sciences stated that the overall rate of violent incidents for all public schools in the United States was 32 incidents per 1000 students [13]. The rate of violent incidents was significantly higher in middle schools ( 52 incidents per 1,000 students) than in primary schools ( 25 incidents per 1,000 students). The institute also reported a $21 \%$ weekly reporting of students bullying [13]. The finding of the study by 
Black [14] is that the prevalence of bullying, cyber bullying \& victimization in his sample of adolescents was high. Over half of the students had taken part in bullying in their lifetime.

Thus, the first two results are an indication regarding the prevalence of bullying in schools and it urges us to be part of some bullying prevention programs that would lead to a better school environment and a happy group of students.

The next section asks the students whether they have stayed away from school in order to avoid being bullied. The results show that 459 students did not stay home to avoid bullying. It indicates that $76.5 \%$ of the children are not victims of bullying. But at the same time, 141 out of the 600 students stay away from school in order to avoid bullying. 23.5 percent of the students are reported to stay home to avoid bullying. This absence from the school is merely because they are victims of bullying. This shows that bullying in schools is an issue that needs immense attention on the part of the authorities.

213 students out of the 600 students reported that they don't really mind about bullying. When it is converted into percentage value, it is found that 35 percent of children are not at all bothered when students get bullied. 23 percent of children who constitute 138 students out of the 600 are bothered a little bit about the bullying incidents. 25.5 percent of children, which come up to 153 among the 600 students, are bothered about bullying some of the time and 16 percent of them, that is, 96 students out of the 600 are bothered to a lot when students get bullied. This is an alarming thing to know that $65 \%$ of the students are concerned about such adverse happenings in the school.

366 children reported that they have not tried to help the victim who was being bullied. This indicates that 61 percent of children have not tried to help the children being bullied. 18.5 of them reported that they have tried to help others once or twice every week, 7 percent of them have reported many times a week and 13.5 of them did not know about it. The result shows that 29 percent of the children have tried to help the other students when they were being bullied.

It may be noted that out of the 600 students included in the study, 486 children reported that bullying occurs in the classrooms. This shows that classrooms are the place where bullying happens the most. It indicates that 81 percent of bullying happens in the classrooms. 33 percent of students reported lunch or eating area as the place where bullying occurs. 15.5 percent of students reported outdoor area around the school as the place where bullying happens. 12.5 percent students reported school bus or ferry as the place where bullying occurs. 10 percent students reported that bullying occurs on the way to and from school. 8.5 percent students reported washrooms to be the place where bullying happens. 7 percent students reported hall ways and library, 4.5 percent students reported Gym, 4 percent students reported computer room and change rooms, 2.5 percent students reported other areas like bus stop or train, 2 percent students reported malls or stores, and 2 percent students reported coat rooms as the place where bullying happen.

It may be noted that 300 students reported that bullying happens during break, lunch or at recess. This place can be considered as the bullying place as it indicates that 50 percent of students felt bullying happens most in break or lunch time. 24 percent reported bullying to happen during classes, 21 percent reported it after school, 17 percent reported it between classes, 13.5 percent reported it before school and 1.5 percent reported it on the weekends. The result shows that most of the bullying happens at the time of break.

\section{CONCLUSION}

It is concluded that there is prevalence of bullying in our schools. Bullying can threaten students' physical and emotional safety at school and can negatively impact their ability to learn. Bullying has to be taken seriously as it has been associated with certain immediate unfavourable consequences for the victims and several victims carry the scars of this victimization through their adult life. Bullying is not just a school problem. It also happens in the community and it requires community support and solutions. Every school exists within a wider community and developing community partnerships to prevent and reduce bullying is an excellent strategy for many reasons.

The outcomes for people who bully others are also not good in the long-term. Children and young people who bully others may come to see bullying as a normal and acceptable way to behave. Those who bully others need support to learn more appropriate ways of behaving and of resolving conflict to prepare them for adulthood and to reduce the likelihood of developing even more serious anti-social behaviours. 
Bullying can be one of the biggest problems for our youth. We need to take responsibility to put an end to this growing dilemma. Our films, entertainers, TV, website, chat rooms etc. all encourage darkened behavior. The statistics of suicide of innocent people who have been the victims of bullying is staggering and alarming. We need to make this issue a priority, whether at home, in school, in the government, or at work. We cannot afford to lose another beautiful soul. There is so much written now concerning this subject. We need to get to the people who bully as quickly as possible. We need to get to them before someone gets hurt.

\section{REFERENCES}

1. Rigby K. Children and bullying: How parents and educators can reduce bullying at school. Blackwell Publishing: UK; 2008.

2. Tattum D, Tattum E. Social education and personal development. Routledge: UK;2017.

3. Olweus D, Limber SP. Bullying in school: Evaluation and dissemination of the Olweus Bullying Prevention Program. Am J Orthopsychiatry 2010;80(1):124-34.

4. Rigby K. Consequences of bullying in schools. Can J Psychiatry 2003;48(9):583-90.

5. Devoe JF, Peter K, Kaufman P, Miller A, Noonan M, Snyder TD, Baum K. Indicators of School Crime and Safety, 2004. NCES 2005-002. National Center for Education Statistics. 2004.

6. Nansel TR, Overpeck M, Pilla RS, Ruan WJ, Simons-Morton B, Scheidt P. Bullying behaviors among US youth: Prevalence and association with psychosocial adjustment. JAMA 2001;285(16):2094-100.

7. Kshirsagar VY, Agarwal R, Bavdekar SB. Bullying in schools: prevalence and short-term impact. Indian Pediatr 2007;44(1):25-8.

8. Ramya SG, Kulkarni ML. Bullying among school children: prevalence and association with common symptoms in childhood. Indian J Pediatr 2011;78(3):307-10.

9. Lawrence C. Social psychology of bullying in the workplace. In Building a Culture of Respect. CRC Press; 2003.

10. Haynie DL, Nansel T, Eitel P, Crump AD, Saylor K, Yu K, Simons-Morton B. Bullies, victims, and bully/victims: Distinct groups of at-risk youth. J Early Adolesc 2001;21(1):29-49.

11. Parault SJ, Davis HA, Pellegrini AD. The social contexts of bullying and victimization. J Early Adolesc 2007;27(2):145-74.

12. Smokowski PR, Kopasz KH. Bullying in school: An overview of types, effects, family characteristics, and intervention strategies. Children and Schools 2005;27(2):101-10.

13. Bowman DH. Survey of students documents the extent of bullying. Education Week 2001;20(33):11.

14. Juvonen J, Graham S. Bullying in Schools: The Power of Bullies and the Plight of Victims. Ann Rev Psychol 2014;65:159-85.

\section{FURTHER RECOMMENED READING}

1. Gredler GR. Olweus, D. Bullying at school: What we know and what we can do. Malden, MA: Blackwell Publishing, 140 pp. Psychology in the Schools 2003;40(6):699-700.

2. Bandura A. Aggression: A school learning analysis. Englewood cliffs, NJ: Prentice-Hall ; 1937.

3. Banks R. Bullying in schools. Campaign on elementary and early childhood Education. (ERIC Digest, EDO-PS-97-17); 1997

4. Batsche GM, Knoff HM. Bullies and their victims: Understanding a pervasive problem in the schools. School Psychol Rev 1994;23:165-90.

5. Bor R, Landy JE, Brace C. Counseling in schools, London: Sage publications ; 2003.

6. Bronfenbrenner U, Evans GW. Developmental science in the 21st century: Emerging questions, theoretical models, research designs and empirical findings. Social Dev 2000;9(1):115-25.

7. Hirchi T. Causes of delinquency. Berkeley and los Angeles : University of California press ; 1969.

8. Hoover JH, Oliver R. The Bullying Prevention Handbook: A Guide for Principals, Teachers, and Counselors.

9. Lines D. Brief counseling in schools working with young people from 11 to 18. London: Sage publications; 2008

10. Thompson AR. School counseling best practices for working in the schools. ( $2^{\text {nd }}$ edition). London: Brunner- Rutledge; 2002.

$$
\begin{aligned}
& \text { Acknowledgements - Nil } \\
& \text { Conflict of Interest - Nil } \\
& \text { Funding - Nil }
\end{aligned}
$$

